\title{
Decompression Using Minimally Invasive Surgery for Lumbar Spinal Stenosis Associated with Degenerative Spondylolisthesis: A Review
}

\author{
Jun Zhang · Tang-Fen Liu · Hua Shan · Zhong-Yuan Wan · Zhe Wang • \\ Omar Viswanath · Antonella Paladini · Giustino Varrassi (D) • \\ Hai-Qiang Wang (D)
}

Received: May 20, 2021 / Accepted: July 12, 2021 / Published online: July 28, 2021

(c) The Author(s) 2021

\begin{abstract}
Lumbar spinal stenosis (LSS), which often occurs concurrently with degenerative spondylolisthesis (DS), is a common disease in the elderly population, affecting the quality of life of aged people significantly. Notwithstanding the frequently good effect of conservative
\end{abstract}

Jun Zhang, Tang-Fen Liu, and Hua Shan contributed equally to the work.

J. Zhang $\cdot$ Z. Wang

Department of Orthopaedics, Baoji Central

Hospital, Baoji 721008, Shaanxi, China

\section{J. Zhang}

School of Public Health, Xi'an Jiaotong University Health Science Center, Xi'an 710061, Shaanxi, China

T.-F. Liu · H. Shan · H.-Q. Wang ( $₫)$

Institute of Integrative Medicine, Shaanxi

University of Chinese Medicine, Xixian District,

Xi'an 712046, Shaanxi, China

e-mail: hqwang@sntcm.edu.cn;

drwanghq@163.com

\section{Z.-Y. Wan}

Department of Orthopedics, The Seventh Medical Center of Chinese PLA General Hospital, Beijing

100700, People's Republic of China

O. Viswanath

Department of Anesthesiology, University of Arizona College of Medicine-Phoenix, Phoenix, AZ, USA therapy on LSS, a minority of the patients ultimately require surgery. Surgery for LSS aims to decompress the narrowed spinal canals with preservation of spinal stability. Traditional open surgery, either pure decompression or decompression with fusion, was considered effective for the treatment of LSS with or without DS. However, the long-term clinical outcomes of traditional open surgery are still unclear. Moreover, the disadvantages of conventional open surgery are extensive, examples including tissue injuries or secondary instability, with

\section{O. Viswanath}

Department of Anesthesiology, Louisiana State

University Health Shreveport, Shreveport, LA, USA

O. Viswanath

Valley Pain Consultants-Envision Physician

Services, Phoenix, AZ, USA

O. Viswanath

Department of Anesthesiology, Creighton

University School of Medicine, Omaha, NE, USA

\author{
A. Paladini \\ Department of MESVA, University of L'Aquila, \\ 67100 L'Aquila, Italy \\ G. Varrassi ( $\square)$ \\ Paolo Procacci Foundation, Via Tacito 7, 00193 \\ Rome, Italy \\ e-mail: giuvarr@gmail.com
}


limited outcomes and significant reoperation rates. With the development and improvement of surgical tools, various minimally invasive spine surgery (MISS) methods, including indirect decompression techniques of interspinous process devices (IPDs) and direct decompression techniques such as microscopic spine surgery or endoscopic spine surgery (ESS), have been updated with enhancement. IPDs, such as Superion devices, were reported to behave with comparable physical function, disability, and symptoms outcomes to laminectomy decompression. As an emerging technique of MISS, ESS has beneficial hallmarks including minimal tissue injuries, reduced complication rates, and shortened recovery periods, thus gaining popularity in recent years. ESS can be classified in terms of endoscopic hallmarks and approaches. Predictably, with the continuous development and gradual maturity, MISS is expected to replace traditional open surgery widely in the surgical treatment of LSS associated with DS in the future.

Keywords: Lumbar spine; Lumbar spinal stenosis; Degenerative spondylolisthesis; Minimally invasive spine surgery; Interspinous process devices; Endoscopic spine surgery; Decompression

$\begin{array}{ll}\text { Abbreviations } \\ \text { BESS } & \text { Biportal endoscopic spinal surgery } \\ \text { CT } & \text { Computed tomography } \\ \text { DS } & \text { Degenerative spondylolisthesis } \\ \text { ESS } & \text { Endoscopic spine surgery } \\ \text { EQ-5D } & \text { EuroQol-5 dimensions } \\ \text { FDA } & \text { Food and Drug Administration } \\ \text { IL } & \text { Interlaminar } \\ \text { IPDs } & \text { Interspinous process devices } \\ \text { LDH } & \text { Lumber disc herniation } \\ \text { LF } & \text { Ligamentum flavum } \\ \text { LSS } & \text { Lumbar spinal stenosis } \\ \text { MED } & \text { Microendoscopic discectomy } \\ \text { MI } & \text { Minimally invasive } \\ \text { MISS } & \text { Minimally invasive spine surgery } \\ \text { MOS } & \text { Medical Outcomes Study } \\ \text { MRI } & \text { Magnetic resonance imaging } \\ \text { ODI } & \text { Oswestry disability index } \\ \text { OL } & \text { Open laminectomy }\end{array}$

PBED Percutaneous biportal endoscopic decompression

PED Percutaneous endoscopic decompression

PELD Percutaneous endoscopic lumbar discectomy

RCT Randomized controlled trial

SAP Superior articular process

SF-36 MOS item short from health survey

TE-LUL Transforaminal full-endoscopic lumbar undercutting laminectomy

TF Transforaminal

UBE Unilateral biportal endoscopic

ULBD Unilateral laminotomy for bilateral decompression

VAS Visual analog scale

ZCQ Zurich Claudication Questionnaire

\section{Key Summary Points}

Spinal pain is highly prevalent.

Conservative therapy is not always efficacious.

Interventional pain management may be beneficial in some cases.

This review is focused on different interventions, especially minimally invasive, used at the moment for persistent low-back pain.

\section{INTRODUCTION}

\section{Overview of Lumbar Spinal Stenosis with Degenerative Spondylolisthesis}

As a common disease for elderly people, lumbar spinal stenosis (LSS) often occurs concurrently with Meyerding grade I to II degenerative spondylolisthesis (DS) [1]. LSS has evolved from an original anatomic perception [2] represented by a clinical syndrome, termed neurologic claudication, and characterized by an intermittent leg pain following a short distance walk. 
Most cases are degenerative, deriving from aging alterations reflected in the spine. During the degenerative process, significant changes gradually occur in multiple intervertebral discs, adjacent structures including the ligamentum flavum (LF), and facet joints, resulting in a reduction of spaces surrounding important neurovascular structures within the spine. The anatomic basis of LSS determines its medical consequences amongst individual cases. LSS can arise at triple sites in terms of orientation with neurovascular structures: spinal canal in the center, lateral recess, as well as neuroforamen. Consequently, it results in symptomatic pain in the back, buttock, and lower extremities, with or without neurologic deficits and related disabilities [3-5].

It is well established that various factors affect the epidemiology of LSS, including socioeconomic conditions, medical care levels, the average life span of countries, personal genetic factors, and others. In the USA, LSS affects more than 200,000 persons, as the most frequent pathologic cause for spinal surgery in patients aged more than 65 years [5]. Epstein [6] reported the prevalence of absolute LSS as $47.2 \%$ for patients $60-69$ years old. Notably, the prevalence elevated with age.

\section{Symptoms and Treatment}

Typical symptoms of LSS include neurogenic claudication, and/or back/leg pain, the underlying mechanisms of which are ascribed to the nerve root compression, and related instability. For cases with early-stage LSS, conservative treatment regimens are generally proposed and accepted for patients without severe neurologic deficits [7]. For cases without efficacy following conservative treatment, the surgical treatment is recommended $[8,9]$. In general, it is reported that $10-15 \%$ of patients ultimately undergo surgery [10].

For patients with lumbar spinal instability reflected by imaging, pure decompression may not solve all existing issues. In this case, decompression plus Dynesys dynamic stabilization or instrumented fusion is more suitable [11]. However, the long-term clinical and radiologic outcomes are still unclear $[10,12]$.

An exact spinal canal decompression is the most important step in the surgical procedure for LSS with DS [13-15]. Open laminectomy (OL) alone is an alternative surgical option for patients with LSS and mild DS without relevant instability on lumbar spine lateral radiographs (Fig. 1) [13, 16-18]. However, open decompression surgery destroys paravertebral soft tissues. From this perspective, minimally invasive (MI) decompression surgery is becoming increasingly popular, especially in Asia. With the development and improvement of surgical tools in recent years, various minimally invasive spine surgery (MISS) has been updated with enhancement. Typical technical updates include interspinous process decompression for indirect spinal canal decompression, microscopy and endoscopy spine surgery for direct spinal canal decompression. Accordingly, this updated review aims to depict the landscape of MI decompression surgical technical advancement, shedding light on the treatment pathways of patients with LSS and/or DS.

This article is based on previously conducted studies and does not contain any new studies with human participants or animals performed by any of the authors. Hence, it does not need any approval of Ethics Committee.

\section{REPORTING STANDARD AND LITERATURE SEARCH}

Given the lack of well-established bona fide guidelines for such literature and/or state-ofthe-art review, we utilized the RAMESES standard [19] for our work based on the PRISMA guideline for systematic review. Moreover, the current review is a combination of our spinal practice $[20,21]$, an update of emerging peerreviewed journals' reports during the past 5 years [22], and thorough searches of electronic databases (Pubmed and EMBASE).

Amongst over 7000 publications from initial searches (using terms as "lumbar spinal stenosis", "degenerative spondylolisthesis", "surgery", "minimally invasive surgical procedures"), we 
screened titles and abstracts of all citations and consequently included 90 studies with full text. Following exclusion of a dozen of irrelevant articles and addition of articles by cross-reference checking, we included 129 articles for the current review. We used Endnote to store citations and included studies, to identify duplicates and integrate evidence according to the subjects of the review.

\section{EMERGING EVIDENCE FOR LSS WITH DS: FUSION OR NOT FUSION}

Hitherto, there has been a continuing debate on the treatment for LSS and/or DS. There are a variety of surgical regimens for LSS and/or DS, including open or minimally invasive decompression, fusion with/without instrumentation $[23,24]$.

Notably, Försth et al. [25], Ghogawala et al. [26], and Peul and Moojen [27] brought a new vision to the clinical community. By randomly assigning 247 patients with LSS and/or DS to decompression alone versus decompression plus fusion groups, Försth et al. [25] found that there was no significant difference in clinical outcomes after 2 and 5 years of observation. Another randomized clinical trial (RCT) reported similar findings regarding the efficacy of adding instrumentation and fusion for DS [26]. Additionally, Peul and Moojen [27] commented on the two trials with emphasis on the necessity of adding a surgical implant.

Besides these lines of evidence, there is additional emerging evidence in favor of the newly formed conclusion. The clinical outcome of 1624 cases with lumbar DS indicated that fusion plus decompression was not superior to decompression alone, according to multiple clinical indicators, i.e., visual analog scale (VAS), the quality-of-life EuroQol-5 Dimensions (EQ-5D), Oswestry disability index (ODI), and the Medical Outcomes Study (MOS) item short form health survey (SF-36) [28].

Collectively, emerging evidence from RCTs presents a novel vision for LSS with DS, highlighting the necessity of fusion with expensive instrumentation.
A

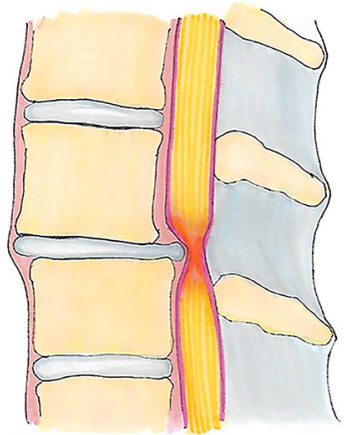

B

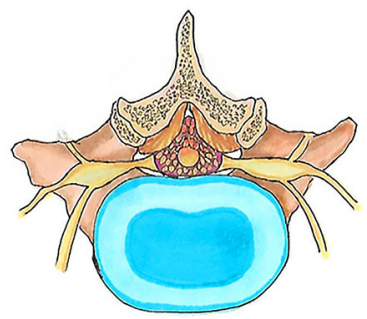

C

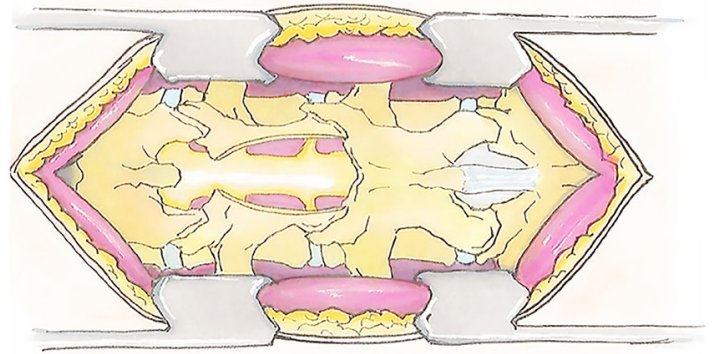

Fig. 1 Schematic lumbar spinal stenosis associated with degenerative spondylolisthesis and open laminectomy decompression surgery. Sagittal (a) and axial (b) images depict the pathologic compression of the cauda equina and/or nerve roots. Schema (c) shows the surgical area of traditional open laminectomy decompression technique

\section{UPDATED MINIMALLY INVASIVE DECOMPRESSION TECHNIQUES}

Given the increasing focusing trend on minimally invasive surgical techniques and the paramount importance of decompression for surgical treatment, we systematically depict updated minimally invasive indirect and direct decompression techniques for LSS associated with DS.

\section{Interspinous Process Decompression}

Interspinous process devices (IPD) have been designed as a minimally invasive indirect decompression technique aiming to decompress the spinal canal and preserve segmental motion. Interspinous process decompression is achieved by placing specific devices between the spinous processes. Accordingly, the volume of the spinal canal can be enlarged indirectly, with the decompression of the spinal cord and 
nerve roots, and the relief of symptoms [29]. IPD originated with the X-STOP device using a new surgical system for indirect decompression of LSS at targeted levels via inserting a device among corresponding spinous processes, achieving a distraction of the spinous processes. Short-term evidence has shown encouraging outcomes for the X-STOP device [30, 31]. Remarkably, considerable complication rates have been noted in terms of long-term observations [32, 33].

Currently available IPDs approved by the US Food and Drug Administration (FDA) include Coflex (Paradigm Spine, Wurmlingen, Germany) and Superion (Vertiflex, Carlsbad, CA, USA), for mild to moderate LSS. Both devices can provide energetic steadiness lacking the rigidity of pedicle screw fixation. An advantage of the Coflex and Superion devices is their percutaneous instrumentation, thus minimizing the disturbance of soft tissues and spinal structure [34, 35]. Compared with traditional decompression and fusion, the 3-year follow-up results after Coflex have proved its cost-effectiveness and safety as an IPD [34]. The Superion device ideally is indicated for patients with LSS who fail conservative treatment before traditional spinal decompression surgery in a flexed position with a Wilson frame, thus basically playing the role of an extension blocker. Studies have shown that, compared with other interspinous spacers and laminectomy, Superion is a MISS technique with a shorter operation time phase, radically reduced blood loss, and lower complication rates [36-38]. In comparison with laminectomy, patients with Superion devices exhibited equivalent physical function, disability, symptom enhancement, and with relatively better improvements. The results were confirmed in a randomized study, showing significantly better outcomes of the patients with Superion compared with X-STOP-implanted patients according to the Zurich Claudication Questionnaire (ZCQ) [36]. Moreover, the Superion group showed no procedure-related complications, no reoperations at the original level up to 3 years after the procedure. In addition, 4and 5-year follow-up studies supported the outcome conclusions [37, 39]. Patients with Superion obtained better indicators (evaluated with ODI) and decreased pain scores compared with baseline. Over time, laminectomy increases the reoperation rate. In contrast, the IPD reoperation rate varied with observational time phases $(14.2 \%$ at 1-year follow-up; $3.2 \%$ at 5 -year follow-up), signifying that early clinical improvement of IPD has foreshadowed the outcome of long-standing continuous clinical benefit [37]. However, the indirect decompression effect after IPDs implantation has the aforementioned advantages over laminectomy decompression.

On the other hand, not all cases with LSS are appropriate for the IPD device. In general, patients with osteoporosis are at risk of spinous process fractures after surgery. In addition, patients with moderate or severe DS, especially with dynamic instability, are at risk of posterior implant movement after surgery. Therefore, these two types of patients with LSS are not appropriate candidates for IPDs [34, 40].

\section{Microscopic Spine Surgery}

The essence of microscopic spine surgery is a MISS that uses a microscope via soft tissue tubular retractor to decompress the spinal canal. Foley et al. [41] introduced their surgical techniques for far-lateral L3 to L5 lumbar disc herniation (LDH) with a $25^{\circ}$ rod-lens endoscope via a $16-\mathrm{mm}$-diameter tubular retractor. Instruments in traditional open discectomy surgery can be used under endoscopic amplification. Historically, Mixter and Barr [42] treated 19 patients with $\mathrm{LDH}$ using total laminectomy and discectomy, considered as a milestone indicating the original open surgical strategies for $\mathrm{LDH}$. As the surgical microscope improved, Caspar [43] and Yaşargil [44] first reported the microdiscectomy procedure from the open posterior approach. Young et al. [45] proposed the unilateral laminotomy for bilateral decompression (ULBD) technique. At present, with the improvements of the microscope and the advancements of surgical techniques, ULBD can be achieved by "over-the-top" technology via various improved tubular retractors (Fig. 2). Microscopic spine surgery can achieve the same 
decompression effect as open surgery, suitable for central and lateral LSS [46-49].

Brief technical key points of ULBD are demonstrated [46, 50]. Microscopic bilateral decompression is achieved under general anesthesia with the knee-thorax position, with the surgical opposite side of the body blocked for later "over-the-top" decompression. After confirming level localization, a 25-30-mm skin incision is made approximately $10-15 \mathrm{~mm}$ from the midline on the side of the approach typically at the lower part of the back (L4 to S1). With a retractor that expands the soft tissue, step-by-step expansion tubular retractors are placed in the operation area. Finally, the working tube is placed in the target area. Intraoperative X-rays play an important role to confirm the correct targeting site for the placement of the tubular retractor as the starting stage of ULBD surgery. The surgical microscope is routinely used to identify the boundary between the LF and inferior rim of the lamina. A balltipped dissector is used to identify the cranial insertion of LF. The ipsilateral LF is removed caudally and thus the dura is decompressed. The tube is angled medially with the operating table tilting against the side of the surgeon, achieving a working and viewing angle of approximately $30^{\circ}$ to conduct over-the-top decompression. With intact contralateral LF, the contralateral lamina is drilled while neural structures are protected by a 9-French Frazier suction tube. Kerrison rongeurs are used for complete resection of the contralateral LF carefully to expose the underlying dural sac. Subsequently, the resection of the ipsilateral LF and hyperplastic articular process is performed. Maintenance of at least half of both facet joints is essential to evade iatrogenic instability [51]. Therefore, microscopic spine surgery is performed via a tube by the over-the-top decompression technique to complete ULBD for LSS.

This minimally invasive procedure achieves sufficient decompression for LSS while limiting surgery-related tissue trauma and aiming to reduce postoperative complications [52, 53]. Several studies comparing ULBD conducted by microscopic surgery with open laminectomy have reported favorable outcomes with the former $[46,54]$. Other trials reported that the microscopic ULBD technique is associated with shortened operation time, less blood loss, shorter hospital stay, and similar clinical outcomes in comparison with open laminectomy [54-57]. However, there are several limitations to microscopic spine surgery. First, difficult instrument manipulation will affect surgeons because of the single port. Second, certain cases may require an excessively tilted microscope and operating table to achieve good contralateral visualization [56, 58]. In addition, there have been concerns regarding limited exposure of microscopic laminectomy, which may lead to inadequate decompression $[46,59]$.

\section{Endoscopic Spine Surgery}

Endoscopic spine surgery (ESS) is a series of minimally invasive surgeries with less associated damage due to continuously improved spinal endoscopes. Evolutions of this technique are well illustrated in a recent publication [60]. In particular, historically Kambin and Hijikata proposed new spinal surgery techniques, "percutaneous lateral discectomy" and "percutaneous nucleosome" for the first time, respectively. They are the earliest pioneers of modern percutaneous spinal endoscopy, thus opening a new chapter of ESS.

Initially, the endoscopic technique was restricted to disc herniations. With the advancement of the endoscopic light source and magnification technology, the indications for ESS have expanded. De Antoni [61] first described a unilateral spinal endoscopy technique behind the lumbar using arthroscopic systems and instruments in 1996, which was named "translaminar lumbar epidural endoscopy" technology. Osman [62] first proposed the operating instruments in the unilateral dual-channel spinal endoscopy technique, which can be independent of the lens and permit larger surgical instruments to remove hardened discs, such as shavers, burs, curettes, trephines, etc. These advantages are an innovation of dual-channel spine endoscopes compared to single-channel spine endoscopes. Therefore, De Antoni and Osman can be 
A

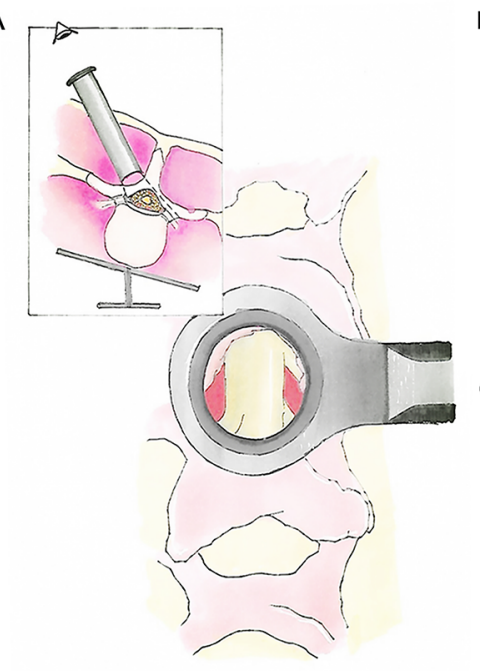

B

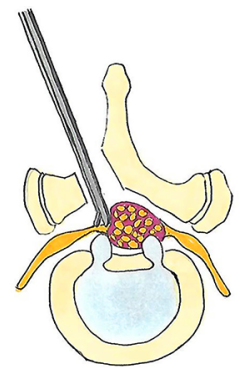

C

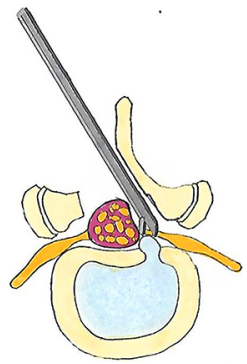

Fig. 2 Schema of the surgical procedure of unilateral laminotomy for bilateral decompression surgical technique. a The operating table is tilted to the opposite side of the surgeon. With the aid of endoscope or microscope, the vision of bilateral visual fields behind the dura mater in the spinal canal is achieved; $\mathbf{b}$ tools are utilized to decompress the spinal canal on the exposed side of the surgical incision; c "over-the-top" technology is adapted to decompress the contralateral side

considered as founders of modern UBE/BESS technology [61, 62].

In recent years, with the successful development of equipment facilities (optics, high-resolution cameras, light source, high-speed burr, irrigation pumps), endoscopy surgery can be performed with various endoscopic techniques for LSS associated with or without DS. Even endoscopic assisted fusion surgeries can achieve satisfactory clinical outcome [63-65]. The pros of endoscopic spinal surgery include less extent of tissue dissection and muscular injuries, enlarged and clearer surgical vision, reduced blood loss, less postoperation epidural fibrosis and scarring, earlier functional recovery, and improved quality of life, reduced hospital stay, and better cosmesis.

There are different procedures for endoscopic techniques according to endoscopes, spinal levels, and surgical approaches. The transforaminal (TF) approach and interlaminar (IL) approach are commonly used in ESS for

decompression (Fig. 3). The most common pathology of the foraminal stenosis and lateral recess stenosis is hypertrophy of the superior articular process (SAP). As a result, the exiting nerve root is compressed in the foraminal stenosis and the traversing nerve root is compressed in the lateral recess stenosis. The transforaminal endoscopic approach commonly is suitable for the treatment of the lateral recess/foraminal stenosis by decompression of the hypertrophied SAP. In 2019, Japanese researchers [66] introduced a developed surgical technique to decompress the central stenosis via the TF approach under local anesthesia. Prior to initiating the clinical case, they attempted the lumbar undercutting laminectomy using a fresh cadaveric spine, then they confirmed that the transforaminal full-endoscopic lumbar undercutting laminectomy (TELUL) is possible, and applied the technique to a 72-year-old woman with central canal stenosis; postoperative follow-up results showed improved leg pain and muscle weakness after TE-LUL under local anesthesia (Fig. 4).

\section{Classification According to the Principle of the Endoscopic System}

\section{Full-Endoscopic (Percutaneous Endoscopic) System}

The full-endoscopic system is also known as the percutaneous endoscopic system. It was first applied in the mid-1980s to treat LDH. The system combines the working pipeline and the optical system to work under continuous saline irrigation. The system is a minimally invasive surgical technique that applies endoscopes to the treatment of spinal diseases (Fig. 5a). In 1999, the intervertebral foraminal endoscope system via Kambin's safety triangle approach was developed, named the Yeung endoscopic spine system (YESS) [67]. This system has provided an important contribution to the development of modern full-endoscopic systems characterized by removing the nucleus pulposus tissue from the inside-to-outside. Nevertheless, its indication is relatively narrow, being only suitable for the treatment of inclusive disc herniation. A further development is represented 
by the transforaminal endoscopic spine system (TESSYS) [68]. The indications for this system are greatly increased and characterized by removing the nucleus pulposus tissue from the outside-to-inside; it can treat various types of LDH and LSS. The percutaneous endoscopic or full-endoscopic system is now most commonly used to treat LDH and LSS, and has become the standard system. With the expansion of surgical indications, the common complications brought by this system, such as dural injury, nerve root injury, postoperative recurrence, etc., require us to rethink and further observe this surgical system.

\section{Microendoscopic System}

Microendoscopic discectomy (MED) is a minimally invasive surgical method performed by using a rigid endoscope (microendoscope) attached to a tubular retractor for the treatment of LDH. MED aims to develop traditional open laminectomy to minimally invasive and endoscopic surgery. With the expansion of its indications, the system has been successfully applied in a wider range of clinical practice such as the treatment of LSS [69-72]. Currently, as an outstanding representative of second-generation MED systems, the METRx tube has incorporated many improvements and become the most widely used MED system (Fig. 5b). However, unlike the full-endoscopic system, the microendoscopic system does not require continuous saline irrigation when operating; therefore, its vision of the surgical area is not as clear as the full-endoscopic system.

\section{Biportal Endoscopic System}

The characteristic of biportal endoscopic system is that unilateral spinal surgery has two independent and cooperating working channelsthe instrumental portal and the endoscopic portal (Fig. 5c) [72-74]. Unilateral biportal endoscopy (UBE)/biportal endoscopic spinal surgery (BESS) decompression technique is a typical technique of the biportal endoscopic system. Choi et al. [75] introduced the use of unilateral dual-channel spinal endoscopy to treat LSS, and named this technique BESS. Immediately after, a different group reported

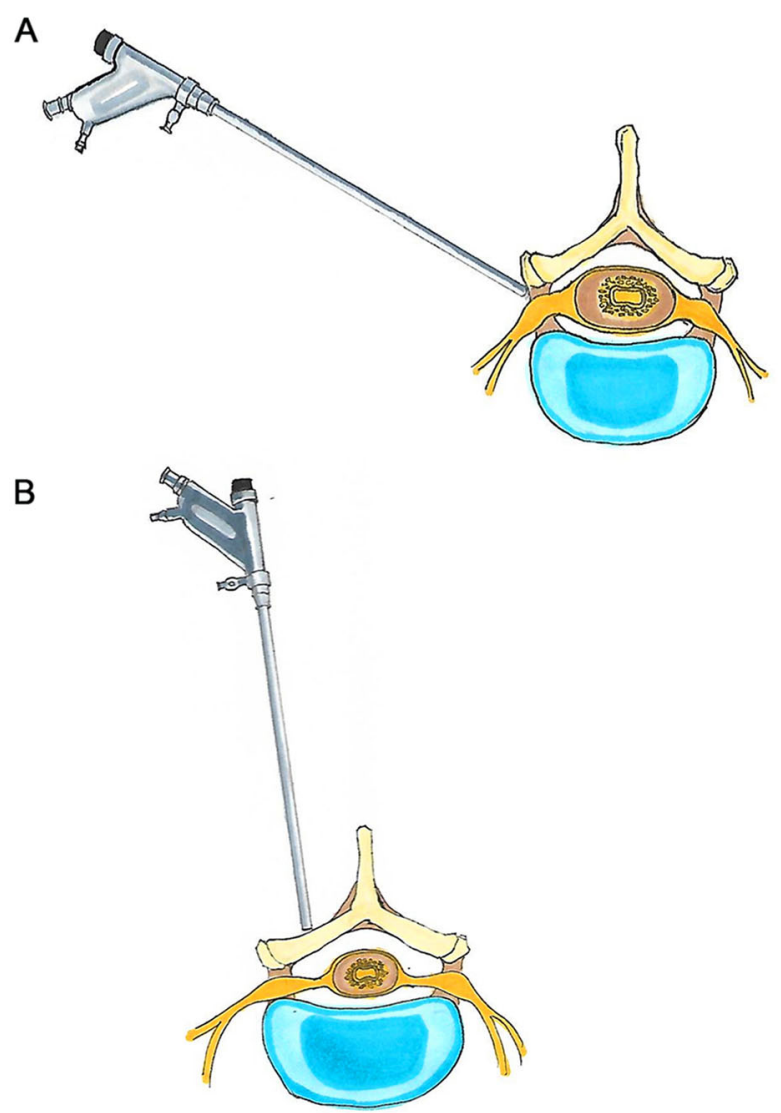

Fig. 3 Two surgical approaches of endoscopic spine surgery. a The transforaminal approach, referring to a posterolateral percutaneous approach to the disc or epidural space via the foraminal window while preserving the normal musculoskeletal structures, usually under local anesthesia; b the interlaminar approach, similar to open laminectomy decompression or microscopic spine surgery, usually under general or epidural anesthesia

their unilateral dual-channel spine endoscopy technique called percutaneous biportal endoscopic decompression (PBED) [73]. The unilateral dual-channel spine endoscopy technology entered a rapid development period promoted by Korean groups, and various improvements were made, including:

- Patient's position changed from lateral to prone

- Application of radiofrequency improved the efficiency of soft tissue processing

- Further expand the indications for this technique: in addition to herniated disc, increased spinal canal stenosis, foraminal 
A

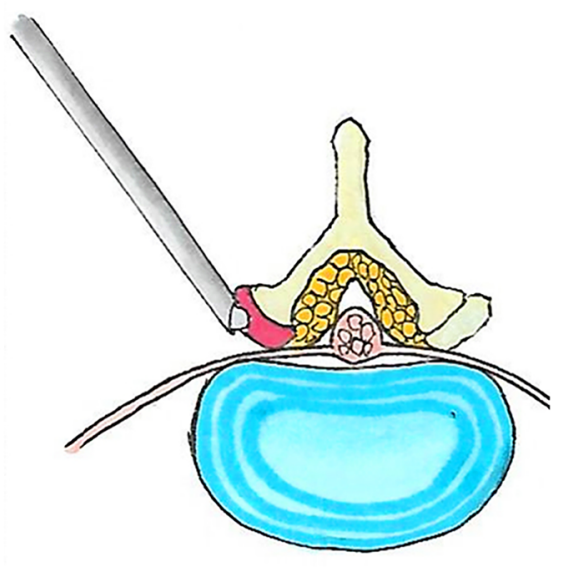

C

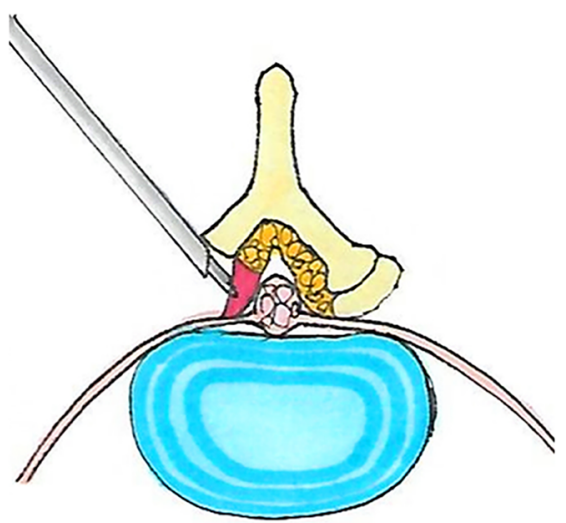

B

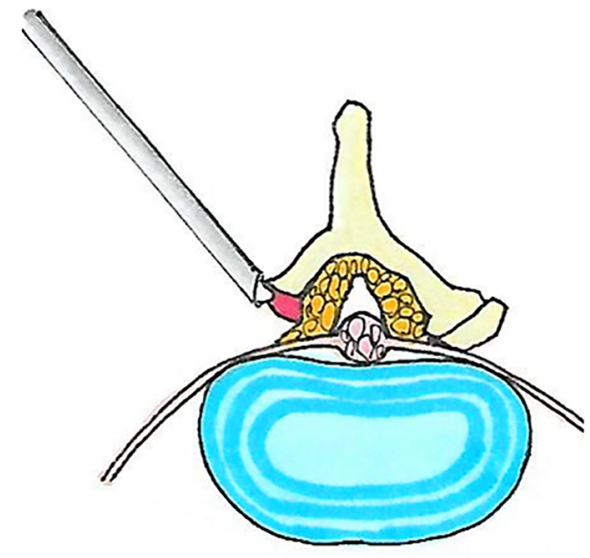

D

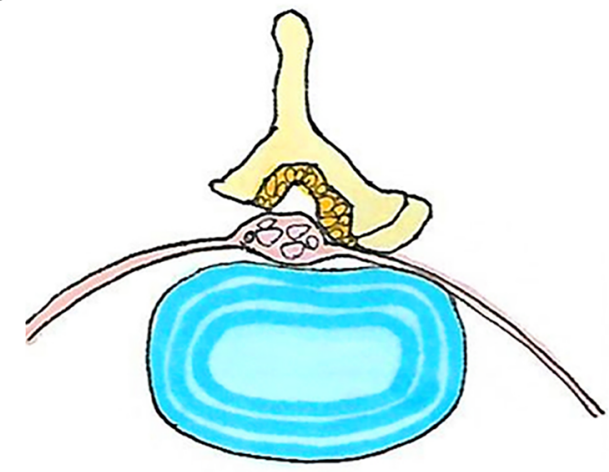

Fig. 4 Key surgical steps of the transforaminal fullendoscopic lumbar undercutting laminectomy technique. a Working cannula is installed as the first step with subsequent whole removal of the superior articular process (colored in red); b undercutting laminectomy and ventral

stenosis, and fusion; and it is no longer only applicable to the lumbar spine but is also applied to the cervical and thoracic spine

- Officially named the surgical procedure as unilateral biportal endoscopy (UBE)

Put simply, UBE and BESS were introduced by doctor groups from different specialties. The two procedures are generally similar, although with slightly different surgical details.

As UBE/BESS has been widely used in recent years, especially in East Asia, its technology began to develop rapidly and various UBE technology-related research projects began to appear. Heo et al. [76] first reported the use of half resection of the inferior articular process (colored in red); $\mathbf{c}$ partial removal of the thickened ligamentum flavum (colored in red); $\mathbf{d}$ the narrowed spinal canal is enlarged following the TE-LUL surgery

UBE for lumbar fusion. Ahn et al. [77] first proposed the extraforaminal approach of UBE to treat foraminal stenosis or extreme lateral disc herniation, which expanded the indications for UBE. Also, Kim et al. [78] reported the application of $30^{\circ}$ arthroscopies and UBE extreme lateral approach for L5 to S1 decompression.

Pao et al. [79] reported that the UBE decompression technique is a safe and effective MI technique. As soft tissue destruction and facet joint destruction can be minimized, it is therefore possible to avoid spinal fusion as well as to preserve the segmental mobility and 

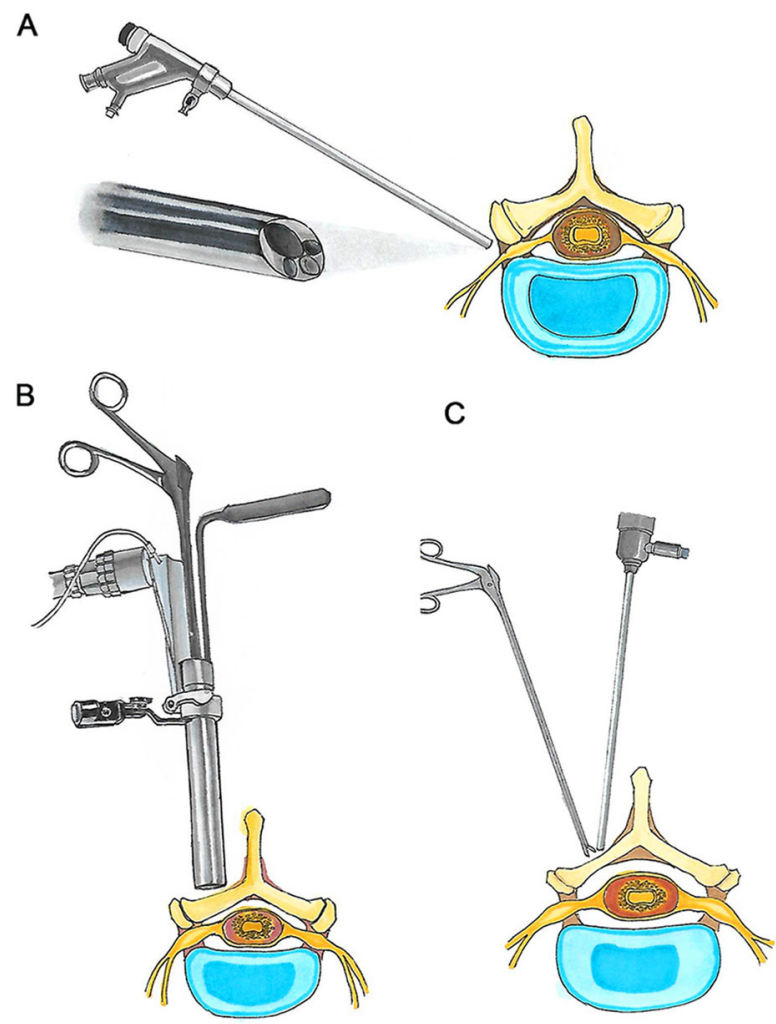

Fig. 5 Categories of the endoscopic system for endoscopic spine surgery. a Percutaneous endoscopic or full-endoscopic system. A working channel endoscope contains a working channel and an optical device within a single portal, which needs continuous saline irrigation for normal working; b microendoscopic system with the optical device attached to the tubular retractor, without needing constant saline irrigation during surgery; c biportal endoscopic system with separate endoscopic working and viewing channels, in need of continuous saline irrigation when operating

stability for patients with LSS associated with or without mild DS. Moreover, the learning curve of UBE/BESS is less steep than for other MI decompression techniques.

\section{DISCUSSION}

LSS is primarily the consequence of pathologically hypertrophic changes of lumbar spinal structures (vertebra, intervertebral discs, facet joints, and LF), reflected as the tightening space of central and lateral canals for neurologic and accompanying vascular elements. Accordingly,
LSS results in an incapacitating compression upon canal-containing neurologic and vascular elements [80, 81]. The number of patients with LSS in need of surgery increases significantly. According to reports, LSS will affect nearly $6,400,000$ aged persons in 5 years [82-84]. LSS frequently arises with low-grade DS (Meyerding grades I and II) [8]. Conservative treatment is the mainstay for LSS with or without DS, including analgesics, anti-inflammatory drugs, low body weight, and physical therapy. Conservative treatment is frequently successful. However, nearly $10-15 \%$ of cases would require surgical treatment because of debilitating pain greatly affecting the quality of life [85].

Surgery for LSS aims to decompress the narrowing canals whilst maintaining important spinal structures and related stability. Sun et al. [86] noted that adequate decompression for LSS associated with DS can be achieved by laminectomy and undercutting decompression, with emphasis on preserving at least half of the involved facet joints to avoid iatrogenic instability. Conventional surgical procedures for LSS comprise open decompression surgery alone or plus fusion. Surgical procedures aim to release the narrowed canals and dural sac by removing hypertrophic bony and soft tissues [87]. For LSS with DS, US clinical guidelines recommend decompression alone and decompression plus fusion [88]. However, so far, there has been controversy regarding the issue. A large number of surgeons consider laminectomy and fusion with added instrumentation as a gold standard for LSS with DS [89]. Notwithstanding the extra expense and certain risks to patients, fusion is mandatory for unstable DS or multisegment decompression. In such scenarios, open surgery per se can cause instability [34]. In a study providing insights into the natural history of DS, the reoperation rate in the DS cohort was $22 \%$ at 8 years [90]. OL alone may lead to a higher reoperation rate and therefore most researchers preferred to choose fixation and fusion surgery or dynamic stabilization to reduce the high reoperation rate that occurs after decompression alone. However, so far, the choice of fusion or non-fusion surgery technique for the treatment of patients with LSS associated with DS is still controversial [16]. 
Decompression with fusion was better in comparison with pure decompression for LSS according to outcome indicators such as ODI and VAS. Syed et al. [91] drew the conclusion that decompression plus fusion is considerably better than pure decompression for LSS. However, it is still controversial which procedures (decompression plus fusion or pure decompression) are superior for the treatment of LSS associated with DS. A couple of RCTs concluded that fusion brings limited value to decompression for LSS associated with or without DS $[25,27]$. A meta-analysis of the literature stated that decompression with fusion is not superior to pure decompression [92]. Moreover, biomechanical testing studies indicated that MI decompression results in a lesser amount of instability in comparison with OL [93, 94]. Simultaneously, a recent study indicated a positively low secondary fusion rate following lumbar MI decompression [95]. Importantly, the issue of secondary fusion rates has not been resolved following open and MI decompression procedures.

In recent years, MIS has gained increased focus in the spinal community with the notion of preserving muscular structures as basic elements for the spine and daily motions $[75,96]$. Recently, there have been updated advancements in MI decompression, including indirect decompression techniques of IPDs and direct decompression techniques such as microscopic spine surgery or ESS. In particular, the ESS has developed more rapidly and has more updated technologies.

IPD is a minimally invasive indirect decompression implant for patients with LSS associated with or without low-grade DS. IPD insertion can expand the narrowed canals with an increment ranging from $18 \%$ to $23 \%$, varying according to different positions [97, 98]. Foramina expansion can be achieved in terms of area and width [99]. The issue of kyphosis due to IPD remains inconclusive [100]. Meta-analysis evidence indicates that IPD had superior clinical outcomes to conservative treatment and comparable outcomes to decompression surgery [101]. Otherwise, IPD can save related expenses. However, the use of IPD is restricted in elderly patients with osteoporosis because of reoperation issues in comparison with decompression [92]. It is currently recognized that severe osteoporosis is a contraindication to IPD because of fracture risks during or after the surgery [100].

In traditional open surgery, the cons include tissue injuries and related instability. Patient outcomes might be compromised with a noteworthy reoperation rate $[56,102-104]$. To address the negative issues, direct MI decompression procedures via microsurgical laminotomy arise, with increasingly wide recognition [105-107]. Representative techniques are ULBD, modified minimally invasive unilateral laminectomy (MIL) with transmuscular tubular retractors [108] (superiority for obese and elder cases $[109,110])$. With researchers' long-term practice and in-depth understanding of the treatment of LSS associated with DS, especially the development in optics facilities, MISS has evolved.

Currently, ESS serves as an extension to the MISS perception of spinal surgery [111-113]. A milestone of spinal endoscopy is the shift from LDH to LSS treatment [53]. Formerly, the main obstacle was the difficulty of sufficient bony and ligament removal with constant visual management [114]. Endoscopic decompression can be achieved by technological improvements [115-117]. Thus, endoscopic spinal decompression surgery is a realistic MI procedure for LSS. ESS can be classified in terms of endoscopic hallmarks and approaches. Among them, IL and TF approaches are two commonly used approaches for spinal canal decompression in patients with LSS.

Various anesthesia regimens are indicated for these procedures. General anesthesia is necessary for IL full-endoscopic surgery; whereas local anesthesia can be applied for the TF approach. In spite of limited and controversial evidence existing for the technique, emerging clinical reports present encouraging evidence [118-121]. While the promising ESS has many advantages, we should also pay attention to the unique risks and complications associated with this minimally invasive technique. Complications from RCTs have been reported regarding ESS for LSS, including revision, transient paresthesia, incidental durotomy, epidural 
hematoma, and infection [122]. Complications in a meta-analysis of ESS were also similar to this RCT study reporting a revision surgery rate of $1.9 \%$ during the follow-up period [123]. It is generally accepted that surgeons' experience plays an important role in reducing complications and improving the outcomes of surgical procedures. ESS requires a sharp learning curve. However, even beginner spine surgeons are familiar with the IL approach.

This study has some limitations. Chronic musculoskeletal pain, and especially low-back pain, is a major burden in everyday clinical practice [124] with emerging concepts for treatment $[125,126]$. Interventional techniques are important, as shown in this review, but we did not take into consideration other alternative therapeutic modalities [127]. Other less invasive, conservative treatments provided interesting results as well [128, 129]. Moreover, we did not consider the spondylolisthesis stage, which was described as important [130]. The topic remains the subject of debate and has inconclusive data. Long-term randomized controlled studies comparing results and side effects with the use of different techniques and methodologies in similar populations would definitely help to provide better results for the suffering patients.

\section{CONCLUSIONS}

LSS is the most frequent spinal pathology among the elderly frequently accompanied with DS. Conservative treatment is a successful method to choose first. However, a number of patients ultimately require surgical treatment because of debilitating back and/or leg pain. Surgery for patients with LSS aims to decompress narrowed spinal canals with preserved spinal stability. As an emerging technique of MISS, ESS has the beneficial hallmarks of less tissue injury, reduced complication rates, and quicker recovery. ESS has gained increasing popularity with wide application in recent years. However, the current evidence is restricted for ESS in LSS in terms of clinical outcome. With the application and development of navigation technology, including optical imaging systems and artificial intelligence in the medical field, it is believed that more effective MI techniques will continue to appear and mature in the surgical treatment of LSS associated with DS in the near future. As well, high-class clinical studies, including RCTs and meta-analyses of the available evidence, are needed to validate the efficacy of emerging surgical techniques. Eventually, ESS could become the golden standard for spinal surgery.

\section{ACKNOWLEDGEMENTS}

Funding. The work was supported by the National Natural Science Foundation of China (Grant Number: 81572182). No other funding or sponsorship was received for this study. The publication of this article was supported by the Paolo Procacci Foundation, 00193 Roma, Italy.

Authorship. All named authors meet the International Committee of Medical Journal Editors (ICMJE) criteria for authorship for this article, take responsibility for the integrity of the work as a whole, and have given their approval for this version to be published.

Author Contributions. HQW and GV conceived of the study. JZ investigated and retrieved the published papers with TFL and HS, as well as wrote the original draft. ZYW, TFL, OV and $\mathrm{HS}$ revised the draft and all references. ZW drew the pictures by hand. All authors have read and agreed to the published version of the manuscript.

Disclosures. Jun Zhang, Tang-Fen Liu, Hua Shan, Zhong-Yuan Wan, Zhe Wang, Omar Viswanath, Antonella Paladini, Giustino Varrassi, and Hai-Qiang Wang have nothing to disclose.

Compliance with Ethics Guidelines. This article is based on previously conducted studies and does not contain any new studies with human participants or animals performed by any of the authors. 
Open Access. This article is licensed under a Creative Commons Attribution-NonCommercial 4.0 International License, which permits any non-commercial use, sharing, adaptation, distribution and reproduction in any medium or format, as long as you give appropriate credit to the original author(s) and the source, provide a link to the Creative Commons licence, and indicate if changes were made. The images or other third party material in this article are included in the article's Creative Commons licence, unless indicated otherwise in a credit line to the material. If material is not included in the article's Creative Commons licence and your intended use is not permitted by statutory regulation or exceeds the permitted use, you will need to obtain permission directly from the copyright holder. To view a copy of this licence, visit http://creativecommons.org/licenses/by$\mathrm{nc} / 4.0 /$.

\section{REFERENCES}

1. Matsudaira K, Yamazaki T, Seichi A, et al. Spinal stenosis in grade I degenerative lumbar spondylolisthesis: a comparative study of outcomes following laminoplasty and laminectomy with instrumented spinal fusion. J Orthop Sci. 2005;10: 270-6. https://doi.org/10.1007/s00776-005-0887-7.

2. Verbiest H. A radicular syndrome from developmental narrowing of the lumbar vertebral canal. Clin Orthop Relat Res. 2001. https://doi.org/10. 1097/00003086-200103000-00002.

3. Kreiner DS, Shaffer WO, Baisden JL, et al. An evidence-based clinical guideline for the diagnosis and treatment of degenerative lumbar spinal stenosis (update). Spine J. 2013;13:734-43. https://doi.org/ 10.1016/j.spinee.2012.11.059.

4. Katz JN, Harris MB. Clinical practice. Lumbar spinal stenosis. N Engl J Med. 2008;358:818-25. https:// doi.org/10.1056/NEJMcp0708097.

5. Lurie J, Tomkins-Lane C. Management of lumbar spinal stenosis. BMJ. 2016;352: h6234. https://doi. org/10.1136/bmj.h6234.

6. Epstein NE. Learning curves for minimally invasive spine surgeries: are they worth it? Surg Neurol Int. 2017;8:61. https://doi.org/10.4103/sni.sni_39_17.
7. Watters WC 3rd, Bono CM, Gilbert TJ, et al. An evidence-based clinical guideline for the diagnosis and treatment of degenerative lumbar spondylolisthesis. Spine J. 2009;9:609-14. https://doi.org/10. 1016/j.spinee.2009.03.016.

8. Weinstein JN, Lurie JD, Tosteson TD, et al. Surgical versus nonsurgical treatment for lumbar degenerative spondylolisthesis. N Engl J Med. 2007;356: 2257-70. https://doi.org/10.1056/NEJMoa070302.

9. Weinstein JN, Lurie JD, Tosteson TD, et al. Surgical compared with nonoperative treatment for lumbar degenerative spondylolisthesis four-year results in the Spine Patient Outcomes Research Trial (SPORT) randomized and observational cohorts. J Bone Jt Surg Am. 2009;91:1295-304. https://doi.org/10. 2106/JBJS.H.00913.

10. Ahmed SI, Javed G, Bareeqa SB, et al. Comparison of decompression alone versus decompression with fusion for stenotic lumbar spine: a systematic review and meta-analysis. Cureus. 2018;10: e3135. https://doi.org/10.7759/cureus.3135.

11. Grob D, Humke T, Dvorak J. Degenerative lumbar spinal stenosis. Decompression with and without arthrodesis. J Bone Jt Surg Am Vol. 1995;77: 1036-41. https://doi.org/10.2106/00004623199507000-00009.

12. Shah M, Kolb B, Yilmaz E, et al. Comparison of lumbar laminectomy alone, lumbar laminectomy and fusion, stand-alone anterior lumbar interbody fusion, and stand-alone lateral lumbar interbody fusion for treatment of lumbar spinal stenosis: a review of the literature. Cureus. 2019;11: e5691. https://doi.org/10.7759/cureus.5691.

13. Overdevest GM, Jacobs W, Vleggeert-Lankamp C, et al. Effectiveness of posterior decompression techniques compared with conventional laminectomy for lumbar stenosis. Cochrane Database Syst Rev. 2015. https://doi.org/10.1002/14651858. CD010036.pub2.

14. Costa F, Anania CD, Zileli M, et al. Lumbar spinal stenosis: introduction to the World Federation of Neurosurgical Societies (WFNS) spine committee recommendations. World Neurosurg X. 2020;7: 100075. https://doi.org/10.1016/j.wnsx.2020. 100075.

15. Fornari M, Robertson SC, Pereira P, et al. Conservative treatment and percutaneous pain relief techniques in patients with lumbar spinal stenosis: WFNS spine committee recommendations. World Neurosurg X. 2020;7: 100079. https://doi.org/10. 1016/j.wnsx.2020.100079.

16. Ilyas H, Udo-Inyang I Jr, Savage J. Lumbar spinal stenosis and degenerative spondylolisthesis: a 
review of the SPORT literature. Clin Spine Surg. 2019;32:272-8. https://doi.org/10.1097/BSD. 0000000000000841.

17. Wang M, Luo XJ, Ye YJ, et al. Does concomitant degenerative spondylolisthesis influence the outcome of decompression alone in degenerative lumbar spinal stenosis? A meta-analysis of comparative studies. World Neurosurg. 2019;123:226-38. https://doi.org/10.1016/j.wneu.2018.11.246.

18. Guigui P, Ferrero E. Surgical treatment of degenerative spondylolisthesis. Orthop Traumatol Surg Res. 2017;103:S11-20. https://doi.org/10.1016/j.otsr. 2016.06.022.

19. Wong G, Greenhalgh T, Westhorp G, et al. RAMESES publication standards: meta-narrative reviews. BMC Med. 2013;11:20. https://doi.org/10.1186/ 1741-7015-11-20.

20. Wang HQ, Mak KC, Samartzis D, et al. "Spring-back" closure associated with open-door cervical laminoplasty. Spine J. 2011;11:832-8. https://doi.org/10. 1016/j.spinee.2011.07.026.

21. Hui H, Luo ZJ, Yan M, et al. Non-fusion and growing instrumentation in the correction of congenital spinal deformity associated with split spinal cord malformation: an early follow-up outcome. Eur Spine J. 2013;22:1317-25. https://doi.org/10.1007/ s00586-013-2757-x.

22. Li XK, Wu ZG, Wang HQ. Adolescent idiopathic scoliosis in China: an ongoing warm debate from bedside to public. Spine (Phila Pa 1976). 2016;41: 369-70. 0000000000001236.

23. O'Leary TJ, Slutsky JR, Bernard MA. Comparative effectiveness research priorities at federal agencies: the view from the Department of Veterans Affairs, National Institute on Aging, and Agency for Healthcare Research and Quality. J Am Geriatr Soc. 2010;58:1187-92. https://doi.org/10.1111/j.15325415.2010.02939.x.

24. Hussein M, Abdeldayem A, Mattar MM. Surgical technique and effectiveness of microendoscopic discectomy for large uncontained lumbar disc herniations: a prospective, randomized, controlled study with 8 years of follow-up. Eur Spine J. 2014;23:1992-9. https://doi.org/10.1007/s00586014-3296-9.

25. Försth $P$, Olafsson $G$, Carlsson $T$, et al. A randomized, controlled trial of fusion surgery for lumbar spinal stenosis. N Engl J Med. 2016;374:1413-23. https://doi.org/10.1056/NEJMoa1513721.

26. Ghogawala Z, Dziura J, Butler WE, et al. Laminectomy plus fusion versus laminectomy alone for lumbar spondylolisthesis. N Engl J Med. 2016;374: 1424-34. https://doi.org/10.1056/NEJMoa1508788.

27. Peul WC, Moojen WA. Fusion for lumbar spinal stenosis-safeguard or superfluous surgical implant? N Engl J Med. 2016;374:1478-9. https://doi.org/10. 1056/NEJMe1600955.

28. Sigmundsson FG, Jonsson B, Stromqvist B. Outcome of decompression with and without fusion in spinal stenosis with degenerative spondylolisthesis in relation to preoperative pain pattern: a register study of 1,624 patients. Spine J. 2015;15:638-46. https://doi.org/10.1016/j.spinee.2014.11.020.

29. Yoshihara H. Indirect decompression in spinal surgery. J Clin Neurosci. 2017;44:63-8. https://doi.org/ 10.1016/j.jocn.2017.06.061.

30. Bao BX, Zhou JW, Yu PF, et al. Transforaminal endoscopic discectomy and foraminoplasty for treating central lumbar stenosis. Orthop Surg. 2019;11:1093-100. https://doi.org/10.1111/os. 12559.

31. Liu X. A novel biportal full endoscopy technique for lumbar lateral recess stenosis: technical report. Clin Spine Surg. 2019;32:51-6. https://doi.org/10.1097/ BSD.0000000000000667.

32. Diwan S, Sayed D, Deer TR, et al. An algorithmic approach to treating lumbar spinal stenosis: an evidenced-based approach. Pain Med. 2019;20: S23-31. https://doi.org/10.1093/pm/pnz133.

33. Overdevest G, Vleggeert-Lankamp C, Jacobs W, et al. Effectiveness of posterior decompression techniques compared with conventional laminectomy for lumbar stenosis. Eur Spine J. 2015;24: 2244-63. https://doi.org/10.1007/s00586-015-40984.

34. Cairns K, Deer T, Sayed D, et al. Cost-effectiveness and safety of interspinous process decompression (Superion). Pain Med. 2019;20:S2-8. https://doi. org/10.1093/pm/pnz245.

35. Gala RJ, Russo GS, Whang PG. Interspinous implants to treat spinal stenosis. Curr Rev Musculoskelet Med. 2017;10:182-8. https://doi.org/10. 1007/s12178-017-9413-8.

36. Patel VV, Nunley PD, Whang PG, et al. Superion(®) InterSpinous Spacer for treatment of moderate degenerative lumbar spinal stenosis: durable threeyear results of a randomized controlled trial. J Pain Res. 2015;8:657-62. https://doi.org/10.2147/JPR. S92633.

37. Nunley PD, Patel VV, Orndorff DG, et al. Five-year durability of stand-alone interspinous process decompression for lumbar spinal stenosis. Clin 
Interv Aging. 2017;12:1409-17. https://doi.org/10. 2147/CIA.S143503.

38. Nunley PD, Patel VV, Orndorff DG, et al. Interspinous process decompression improves quality of life in patients with lumbar spinal stenosis. Minim Invasive Surg. 2018;2018:1035954. https://doi.org/ $10.1155 / 2018 / 1035954$.

39. Nunley PD, Patel VV, Orndorff DG, et al. Superion interspinous spacer treatment of moderate spinal stenosis: 4-year results. World Neurosurg. 2017;104: 279-83. https://doi.org/10.1016/j.wneu.2017.04. 163.

40. Zini C, Bellini M, Masala S, et al. Percutaneous interspinous spacer in spinal-canal-stenosis treatment: pros and cons. Medicina (Kaunas). 2019. https://doi.org/10.3390/medicina55070381.

41. Foley KT, Smith MM, Rampersaud YR. Microendoscopic approach to far-lateral lumbar disc herniation. Neurosurg Focus. 1999;7: e5. https://doi.org/ 10.3171/foc.1999.7.6.6.

42. Mixter WJ, Barr JS. Rupture of the intervertebral disc with involvement of the spinal canal. N Engl J Med. 1934;211:210-5.

43. Caspar W. Actovegin in myelopathies. Clinical experiences with actovegin in spinal cord disorders due to compression and circulation problems. Fortschr Med. 1978;96:887-8.

44. Yasargil MG, Vise WM, Bader DC. Technical adjuncts in neurosurgery. Surg Neurol. 1977;8: 331-6.

45. Young S, Veerapen R, O'Laoire SA. Relief of lumbar canal stenosis using multilevel subarticular fenestrations as an alternative to wide laminectomy: preliminary report. Neurosurgery. 1988;23:628-33. https://doi.org/10.1227/00006123-19881100000014.

46. Phan K, Mobbs RJ. Minimally invasive versus open laminectomy for lumbar stenosis: a systematic review and meta-analysis. Spine (Phila $\mathrm{Pa}$ 1976). 2016;41:E91-100. https://doi.org/10.1097/BRS. 0000000000001161.

47. Chen T, Zhou G, Chen Z, et al. Biportal endoscopic decompression vs. microscopic decompression for lumbar canal stenosis: a systematic review and meta-analysis. Exp Ther Med. 2020;20:2743-51. https://doi.org/10.3892/etm.2020.9001.

48. Hussain I, Kirnaz S, Wibawa G, et al. Minimally invasive approaches for surgical treatment of lumbar spondylolisthesis. Neurosurg Clin $\mathrm{N}$ Am. 2019;30:305-12. https://doi.org/10.1016/j.nec. 2019.02.004.
49. Wang R, Li X, Zhang X, et al. Microscopic decompressive laminectomy versus percutaneous endoscopic decompressive laminectomy in patients with lumbar spinal stenosis: protocol for a systematic review and meta-analysis. BMJ Open. 2020;10: e037096. https://doi.org/10.1136/bmjopen-2020037096.

50. Korge A, Mehren C, Ruetten S. Erratum zu: Minimal-invasive Dekompressionsverfahren der Spinalkanalstenose. Orthopade. 2020;49:190. https://doi.org/10.1007/s00132-020-03869-w.

51. Deer T, Sayed D, Michels J, et al. A review of lumbar spinal stenosis with intermittent neurogenic claudication: disease and diagnosis. Pain Med. 2019;20: S32-44. https://doi.org/10.1093/pm/pnz161.

52. Yagi M, Okada E, Ninomiya K, et al. Postoperative outcome after modified unilateral-approach microendoscopic midline decompression for degenerative spinal stenosis. J Neurosurg Spine. 2009;10:293-9. https://doi.org/10.3171/2009.1. SPINE08288.

53. Ahn Y. Percutaneous endoscopic decompression for lumbar spinal stenosis. Expert Rev Med Devices. 2014;11:605-16. https://doi.org/10.1586/17434440. 2014.940314.

54. Rahman M, Summers LE, Richter B, et al. Comparison of techniques for decompressive lumbar laminectomy: the minimally invasive versus the "classic" open approach. Minim Invasive Neurosurg. 2008;51:100-5. https://doi.org/10.1055/s2007-1022542.

55. Ko S, Oh T. Comparison of bilateral decompression via unilateral laminotomy and conventional laminectomy for single-level degenerative lumbar spinal stenosis regarding low back pain, functional outcome, and quality of life-a randomized controlled, prospective trial. J Orthop Surg Res. 2019;14:252. https://doi.org/10.1186/s13018-0191298-3.

56. Thome C, Zevgaridis D, Leheta O, et al. Outcome after less-invasive decompression of lumbar spinal stenosis: a randomized comparison of unilateral laminotomy, bilateral laminotomy, and laminectomy. J Neurosurg Spine. 2005;3:129-41. https:// doi.org/10.3171/spi.2005.3.2.0129.

57. Palmer S, Turner R, Palmer R. Bilateral decompression of lumbar spinal stenosis involving a unilateral approach with microscope and tubular retractor system. J Neurosurg. 2002;97:213-7. https://doi. org/10.3171/spi.2002.97.2.0213.

58. Min WK, Kim JE, Choi DJ, et al. Clinical and radiological outcomes between biportal endoscopic decompression and microscopic decompression in 
lumbar spinal stenosis. J Orthop Sci. 2020;25:371-8. https://doi.org/10.1016/j.jos.2019.05.022.

59. Knotkova H, Fine PG, Portenoy RK. Opioid rotation: the science and the limitations of the equianalgesic dose table. J Pain Symptom Manag. 2009;38: 426-39. https://doi.org/10.1016/j.jpainsymman. 2009.06.001.

60. Khandge AV, Sharma SB, Kim JS. The evolution of transforaminal endoscopic spine surgery. World Neurosurg. 2021;145:643-56. https://doi.org/10. 1016/j.wneu.2020.08.096.

61. De Antoni DJ, Claro ML, Poehling GG, et al. Translaminar lumbar epidural endoscopy: anatomy, technique, and indications. Arthroscopy. 1996;12: 330-4. 8063(96)90069-9.

62. Osman SG, Schwartz JA, Marsolais EB. Arthroscopic discectomy and interbody fusion of the thoracic spine: a report of ipsilateral 2-portal approach. Int J Spine Surg. 2012;6:103-9. https://doi.org/10.1016/j. ijsp.2012.02.004.

63. Minamide A, Yoshida $M$, Yamada $H$, et al. Rethinking surgical treatment of lumbar spondylolisthesis. Neurosurg Clin N Am. 2019;30:323-31. https://doi.org/10.1016/j.nec.2019.02.006.

64. Weiss H, Garcia RM, Hopkins B, et al. A systematic review of complications following minimally invasive spine surgery including transforaminal lumbar interbody fusion. Curr Rev Musculoskelet Med. 2019. https://doi.org/10.1007/s12178-019-09574-2.

65. Sharif S, Shaikh Y, Bajamal AH, et al. Fusion surgery for lumbar spinal stenosis: WFNS spine committee recommendations. World Neurosurg X. 2020;7: 100077 . https://doi.org/10.1016/j.wnsx.2020. 100077.

66. Sairyo K, Yamashita K, Manabe H, et al. A novel surgical concept of transforaminal full-endoscopic lumbar undercutting laminectomy (TE-LUL) for central canal stenosis of the lumbar spine with local anesthesia: a case report and literature review. J Med Invest. 2019;66:224-9. https://doi.org/10.2152/jmi. 66.224 .

67. Pan M, Li Q, Li S, Mao H, et al. Percutaneous endoscopic lumbar discectomy: Indications and complications. Pain Phys. 2020;23(1):49-56.

68. He S, Sun Z, Wang Y, Ma D, et al. Combining YESS and TESSYS techniques during percutaneous transforaminal endoscopic discectomy for multilevel lumbar disc herniation. Medicine (Baltimore). 2018;97(28): e11240. https://doi.org/10.1097/MD. 0000000000011240 .
69. Muramatsu K, Hachiya Y, Morita C. Postoperative magnetic resonance imaging of lumbar disc herniation: comparison of microendoscopic discectomy and Love's method. Spine (Phila Pa 1976). 2001;26: 1599-605. https://doi.org/10.1097/00007632200107150-00022.

70. Khoo LT, Fessler RG. Microendoscopic decompressive laminotomy for the treatment of lumbar stenosis. Neurosurgery. 2002;51:S146-154.

71. Schick U, Dohnert J, Richter A, et al. Microendoscopic lumbar discectomy versus open surgery: an intraoperative EMG study. Eur Spine J. 2002;11: 20-6. https://doi.org/10.1007/s005860100315.

72. Perez-Cruet MJ, Foley KT, Isaacs RE, et al. Microendoscopic lumbar discectomy: technical note. Neurosurgery. 2002;51:S129-136.

73. Hwa Eum J, Hwa Heo D, Son SK, et al. Percutaneous biportal endoscopic decompression for lumbar spinal stenosis: a technical note and preliminary clinical results. J Neurosurg Spine. 2016;24:602-7. https://doi.org/10.3171/2015.7.SPINE15304.

74. Eun SS, Eum JH, Lee SH, et al. Biportal endoscopic lumbar decompression for lumbar disk herniation and spinal canal stenosis: a technical note. J Neurol Surg A Cent Eur Neurosurg. 2017;78:390-6. https:// doi.org/10.1055/s-0036-1592157.

75. Choi CM, Chung JT, Lee SJ, et al. How I do it? Biportal endoscopic spinal surgery (BESS) for treatment of lumbar spinal stenosis. Acta Neurochir (Wien). 2016;158:459-63. https://doi.org/10.1007/ s00701-015-2670-7.

76. Heo DH, Son SK, Eum JH, et al. Fully endoscopic lumbar interbody fusion using a percutaneous unilateral biportal endoscopic technique: technical note and preliminary clinical results. Neurosurg Focus. 2017;43:E8. https://doi.org/10.3171/2017.5. FOCUS17146.

77. Ahn JS, Lee HJ, Choi DJ, et al. Extraforaminal approach of biportal endoscopic spinal surgery: a new endoscopic technique for transforaminal decompression and discectomy. J Neurosurg Spine. 2018;28:492-8. https://doi.org/10.3171/2017.8. SPINE17771.

78. Kim JE, Choi DJ. Bi-portal arthroscopic spinal surgery (BASS) with 30 degrees arthroscopy for far lateral approach of L5-S1-technical note. J Orthop. 2018;15:354-8. https://doi.org/10.1016/j.jor.2018. 01.034 .

79. Pao JL, Lin SM, Chen WC, et al. Unilateral biportal endoscopic decompression for degenerative lumbar canal stenosis. J Spine Surg. 2020;6:438-46. https:// doi.org/10.21037/jss.2020.03.08. 
80. Deasy J. Acquired lumbar spinal stenosis. JAAPA. 2015;28:19-23. https://doi.org/10.1097/01.JAA. 0000462052.47882.fd.

81. Oba H, Tsutsumimoto T, Yui M, et al. A prospective study of recovery from leg numbness following decompression surgery for lumbar spinal stenosis. J Orthop Sci. 2017;22:670-5. https://doi.org/10. 1016/j.jos.2017.04.004.

82. Lee $\mathrm{CH}$, Chung $\mathrm{CK}$, $\mathrm{Kim} \mathrm{CH}$, et al. Health care burden of spinal diseases in the Republic of Korea: analysis of a nationwide database from 2012 through 2016. Neurospine. 2018;15:66-76. https:// doi.org/10.14245/ns.1836038.019.

83. Latina R, De Marinis MG, Giordano F, Osborn JF, et al. Epidemiology of chronic pain in the Latium Region, Italy: a cross-sectional study on the clinical characteristics of patients attending pain clinics. Pain Man Nurs. 2019. https://doi.org/10.1016/j. pmn.2019.01.005.

84. Kim JH, Kwon YJ. Long-term clinical and radiological outcomes after central decompressive laminoplasty for lumbar spinal stenosis. Korean J Spine. 2017;14:71-6. https://doi.org/10.14245/kjs.2017. 14.3.71.

85. Kelleher MO, Timlin M, Persaud O, et al. Success and failure of minimally invasive decompression for focal lumbar spinal stenosis in patients with and without deformity. Spine (Phila Pa 1976). 2010;35: E981-987. https://doi.org/10.1097/BRS. 0b013e3181c46fb4.

86. Sun W, Xue C, Tang XY, et al. Selective versus multi-segmental decompression and fusion for multi-segment lumbar spinal stenosis with singlesegment degenerative spondylolisthesis. J Orthop Surg Res. 2019;14:46. https://doi.org/10.1186/ s13018-019-1092-2.

87. Ulrich NH, Burgstaller JM, Pichierri G, et al. Decompression surgery alone versus decompression plus fusion in symptomatic lumbar spinal stenosis: a swiss prospective multicenter cohort study with 3 years of follow-up. Spine (Phila Pa 1976). 2017;42: E1077-86. 0000000000002068 .

88. Resnick DK, Watters WC 3rd, Sharan A, et al. Guideline update for the performance of fusion procedures for degenerative disease of the lumbar spine. Part 9: lumbar fusion for stenosis with spondylolisthesis. J Neurosurg Spine. 2014;21: 54-61. https://doi.org/10.3171/2014.4.SPINE14274.

89. Eismont FJ, Norton RP, Hirsch BP. Surgical management of lumbar degenerative spondylolisthesis. J Am Acad Orthop Surg. 2014;22:203-13. https:// doi.org/10.5435/JAAOS-22-04-203.
90. Gerling MC, Leven D, Passias PG, et al. Risk factors for reoperation in patients treated surgically for degenerative spondylolisthesis: a subanalysis of the 8 -year data from the SPORT trial. Spine (Phila Pa 1976). 2017;42:1559-69. https://doi.org/10.1097/ BRS.0000000000002196.

91. Syed S, Telfeian AE, Houle P, Wagner R, et al. Four complications associated with lateral and oblique fusion treatable with endoscopic spine surgery: technical note and case series. Pain Phys. 2020;23(6):E665-71.

92. Machado GC, Ferreira PH, Harris IA, et al. Effectiveness of surgery for lumbar spinal stenosis: a systematic review and meta-analysis. PLoS ONE. 2015;10: e0122800. https://doi.org/10.1371/ journal.pone.0122800.

93. Bresnahan L, Ogden AT, Natarajan RN, et al. A biomechanical evaluation of graded posterior element removal for treatment of lumbar stenosis: comparison of a minimally invasive approach with two standard laminectomy techniques. Spine (Phila Pa 1976). 2009;34:17-23. https://doi.org/10.1097/ BRS.0b013e318191438b.

94. Smith ZA, Vastardis GA, Carandang G, et al. Biomechanical effects of a unilateral approach to minimally invasive lumbar decompression. PLoS ONE. 2014;9: e92611. https://doi.org/10.1371/ journal.pone.0092611.

95. Alimi M, Hofstetter CP, Pyo SY, et al. Minimally invasive laminectomy for lumbar spinal stenosis in patients with and without preoperative spondylolisthesis: clinical outcome and reoperation rates. J Neurosurg Spine. 2015;22:339-52. https://doi.org/ 10.3171/2014.11.SPINE13597.

96. Guiot BH, Khoo LT, Fessler RG. A minimally invasive technique for decompression of the lumbar spine. Spine (Phila Pa 1976). 2002;27:432-8. https:// doi.org/10.1097/00007632-200202150-00021.

97. Siddiqui M, Karadimas E, Nicol M, et al. Influence of $\mathrm{X}$ Stop on neural foramina and spinal canal area in spinal stenosis. Spine (Phila Pa 1976). 2006;31: 2958-62. https://doi.org/10.1097/01.brs. $0000247797.92847 .7 \mathrm{~d}$.

98. Richards JC, Majumdar S, Lindsey DP, et al. The treatment mechanism of an interspinous process implant for lumbar neurogenic intermittent claudication. Spine (Phila Pa 1976). 2005;30:744-9. https://doi.org/10.1097/01.brs.0000157483.28505. e3.

99. Lazaro BC, Brasiliense LB, Sawa AG, et al. Biomechanics of a novel minimally invasive lumbar interspinous spacer: effects on kinematics, facet loads, and foramen height. Neurosurgery. 2010;66: 
126-32. https://doi.org/10.1227/01.NEU.00003485 61.59062.A2 (discussion 132-123).

100. Alfieri A, Gazzeri R, Prell J, et al. Role of lumbar interspinous distraction on the neural elements. Neurosurg Rev. 2012;35:477-84. https://doi.org/10. 1007/s10143-012-0394-1 (discussion 484).

101. Wu AM, Zhou Y, Li QL, et al. Interspinous spacer versus traditional decompressive surgery for lumbar spinal stenosis: a systematic review and meta-analysis. PLoS ONE. 2014;9: e97142. https://doi.org/10. 1371/journal.pone.0097142.

102. Airaksinen O, Herno A, Kaukanen E, et al. Density of lumbar muscles 4 years after decompressive spinal surgery. Eur Spine J. 1996;5:193-7. https:// doi.org/10.1007/BF00395513.

103. Postacchini F, Cinotti G, Perugia D, et al. The surgical treatment of central lumbar stenosis. Multiple laminotomy compared with total laminectomy. J Bone Jt Surg Br. 1993;75:386-92. https://doi.org/ 10.1302/0301-620X.75B3.8496205.

104. Radcliff K, Curry P, Hilibrand A, et al. Risk for adjacent segment and same segment reoperation after surgery for lumbar stenosis: a subgroup analysis of the Spine Patient Outcomes Research Trial (SPORT). Spine (Phila Pa 1976). 2013;38:531-9. https://doi.org/10.1097/BRS.0b013e31827c99f0.

105. Kleeman TJ, Hiscoe AC, Berg EE. Patient outcomes after minimally destabilizing lumbar stenosis decompression: the "Port-Hole" technique. Spine (Phila Pa 1976). 2000;25:865-70. https://doi.org/10. 1097/00007632-200004010-00016.

106. Poletti CE. Central lumbar stenosis caused by ligamentum flavum: unilateral laminotomy for bilateral ligamentectomy: preliminary report of two cases. Neurosurgery. 1995;37:343-7. https://doi. org/10.1227/00006123-199508000-00025.

107. Spetzger U, Bertalanffy $H$, Naujokat C, et al. Unilateral laminotomy for bilateral decompression of lumbar spinal stenosis. Part I: anatomical and surgical considerations. Acta Neurochir (Wien). 1997;139:392-6. https://doi.org/10.1007/ BF01808872.

108. Palmer S, Turner R, Palmer R. Bilateral decompressive surgery in lumbar spinal stenosis associated with spondylolisthesis: unilateral approach and use of a microscope and tubular retractor system. Neurosurg Focus. 2002;13:E4. https://doi.org/10.3171/ foc.2002.13.1.5.

109. Rosen DS, O'Toole JE, Eichholz KM, et al. Minimally invasive lumbar spinal decompression in the elderly: outcomes of 50 patients aged 75 years and older. Neurosurgery. 2007;60:503-9. https://doi.
org/10.1227/01.NEU.0000255332.87909.58 (discussion 509-510).

110. Tomasino A, Parikh K, Steinberger J, et al. Tubular microsurgery for lumbar discectomies and laminectomies in obese patients: operative results and outcome. Spine (Phila Pa 1976). 2009;34:E664672. 0b013e3181b0b63d.

111. Ruetten S. Full-endoscopic operations of the spine in disk herniations and spinal stenosis. Surg Technol Int. 2011;21:284-98.

112. Kapetanakis S, Giovannopoulou E, Thomaidis T, et al. Transforaminal percutaneous endoscopic discectomy in parkinson disease: preliminary results and short review of the literature. Korean J Spine. 2016;13:144-50. https://doi.org/10.14245/kjs.2016. 13.3.144

113. Mohi Eldin MM, Eissa EM, Elmorsy HM. Safety and efficacy of mini open transforaminal lumbar interbody fusion. Korean J Spine. 2016;13:190-5. https:// doi.org/10.14245/kjs.2016.13.4.190.

114. Torudom Y, Dilokhuttakarn T. Two portal percutaneous endoscopic decompression for lumbar spinal stenosis: preliminary study. Asian Spine J. 2016;10: 335-42. https://doi.org/10.4184/asj.2016.10.2.335.

115. Ruetten S, Komp M, Merk H, et al. Surgical treatment for lumbar lateral recess stenosis with the fullendoscopic interlaminar approach versus conventional microsurgical technique: a prospective, randomized, controlled study. J Neurosurg Spine. 2009;10:476-85. https://doi.org/10.3171/2008.7. 17634.

116. Yue JJ, Long W. Full endoscopic spinal surgery techniques: advancements, indications, and outcomes. Int J Spine Surg. 2015;9:17. https://doi.org/ $10.14444 / 2017$.

117. Choi G, Pophale CS, Patel B, et al. Endoscopic spine surgery. J Korean Neurosurg Soc. 2017;60:485-97. https://doi.org/10.3340/jkns.2017.0203.004.

118. Wu J, Guan T, Tian F, et al. Comparision of biportal endoscopic and microscopic decompression in treatment of lumbar spinal stenosis: a comparative study protocol. Medicine (Baltimore). 2020;99: e21309. https://doi.org/10.1097/MD.00000000000 21309.

119. Lee C-H, Chooi M, Ryu DS, et al. Efficacy and safety of full-endoscopic decompression via interlaminar approach for central or lateral recess spinal stenosis of the lumbar spine: a meta-analysis. Spine. 2018;43(24):1756-64. https://doi.org/10.1097/BRS. 0000000000002708 . 
120. Korge A, Mehren C, Ruetten S. Minimally invasive decompression techniques for spinal cord stenosis. Orthopade. 2019;48:824-30. https://doi.org/10. 1007/s00132-019-03732-7.

121. Li XF, Jin LY, Lv ZD, et al. Endoscopic ventral decompression for spinal stenosis with degenerative spondylolisthesis by partially removing posterosuperior margin underneath the slipping vertebral body: technical note and outcome evaluation. World Neurosurg. 2019;126:e517-25. https://doi. org/10.1016/j.wneu.2019.02.083.

122. Komp M, Hahn P, Oezdemir S, et al. Bilateral spinal decompression of lumbar central stenosis with the full-endoscopic interlaminar versus microsurgical laminotomy technique: a prospective, randomized, controlled study. Pain Physician. 2015;18:61-70.

123. Lee CH, Choi M, Ryu DS, et al. Efficacy and safety of full-endoscopic decompression via interlaminar approach for central or lateral recess spinal stenosis of the lumbar spine: a meta-analysis. Spine (Phila Pa 1976). 2018;43:1756-64. https://doi.org/10.1097/ BRS.0000000000002708.

124. Camilloni A, Nati G, Maggiolini P, Romanelli A, et al. Chronic non-cancer pain in primary care: an Italian cross-sectional study. Signa Vitae. 2021;7(2): 54-62. https://doi.org/10.22514/sv.2020.16.0111.

125. Wang HQ, Varrassi G. Emerging basic and clinical studies on musculoskeletal pain and management. Pain Res Manag. 2020. https://doi.org/10.1155/ 2020/4725303.
126. Varrassi G, Moretti B, Pace MC, Evangelista P, Iolascon G. Common clinical practice for low back pain treatment: a modified Delphi study. Pain Ther. 2021. https://doi.org/10.1007/s40122-021-00249-w.

127. Meloncelli S, Germani G, Urti I, Divizia M, et al. Endoscopic radiofrequency facet joint treatment in patients with low back pain: technique and longterm results. A prospective cohort study. Ther Adv Muskuloskelet Dis. 2020. https://doi.org/10.1177/ 1759720x20958979.

128. Vitoula K, Venneri A, Varrassi G, Paladini A, et al. Behavioural therapy approaches for the management of low back pain: an up-to-date systematic review. Pain Ther. 2018;7(1):1-12. https://doi.org/ 10.1007/s40122-018-0099-4.

129. Scaturro D, Asaro C, Lauricella L, Tomasello S, et al. Combination of rehabilitative therapy with ultramicronized palmitoylethanolamide for chronic low back pain: an observational study. Pain Ther. 2020;9(1):319-28. https://doi.org/10.1007/s40122019-00140-9.

130. Minamide A, Simpson AK, Okada $M$, et al. Microendoscopic decompression for lumbar spinal stenosis with degenerative spondylolisthesis: the influence of spondylolisthesis stage (disc height and static and dynamic translation) on clinical outcomes. Clin Spine Surg. 2019;32(1):E20-6. https:// doi.org/10.1097/BSD.0000000000000710. 